\title{
Principles of therapy and care of laboratory animals after chronic administration into
} Xylasine-Zoletyl ${ }^{\circledR}$ Anesthesia

Received: 18 August, 2020

Accepted: 05 September, 2020

Published: 07 September, 2020

*Corresponding author: Karantysh GV, Leading Researcher, Research Technology Center Neurotechnologies, Southern Federal University, Rostov-on-Don, Russia, Tel: Tel: +7-928-138-88-57; E-mail:karantyshgv@mail.ru

Keywords: Xylazine-Zoletil; Anesthesia; Chronic experiment; Laboratory animals

https://www.peertechz.com

Check for updates

\section{Vovk AN, Karantysh GV*, Kosenko PO and Medvedev DS}

Research Technology Center Neurotechnologies, Southern Federal University, Rostov-on-Don, Russia

\begin{abstract}
The use of a combination of dissociative anesthetics and alpha-2-agonists for chronic experiments in laboratory animals is advisable in the case of studying the functions of the limbic system. This requires the development of a protocol for withdrawing animals from this anesthesia, since frequent anesthesia leads to damage to organs and tissues, the need to increase the dose with frequent use of anesthesia, and distortion of the research results. This article provides recommendations for the elimination of chronic xylazine-Zoletil ${ }^{\circledR}$ anesthesia, including pharmacological therapy and additional care measures for experimental animals (based on a comparative analysis of changes in respiration on a pneumogram, the nature of dysfunctions during the period of anesthesia and the mortality rate of animals that were or did not use measures to withdraw from anesthesia).
\end{abstract}

\section{Introduction}

The progress of medicine at the present time is closely related to the need to conduct experimental research on laboratory animals [1]. For humane treatment of animals in laboratory conditions, anesthesia and sedation are used, the combination of which, as well as the technique of their application on animals, are widely described in the literature [2-5]. However, the technology providing the required level of safety of chronic use of anesthesia and sedatives for the health of laboratory animals has not been fully developed. This often leads to damage to organs and tissues and, as a result, distortion of research results and even death of animals. Frequent anesthesia leads to a number of negative consequences at the stage of recovery from anesthesia: severe salivation, bronchial hypersecretion, the development of apnea, as well as tolerance to anesthesia drugs and, as a result, the need to increase the dose of drug to achieve the desired effect [6].

To neutralize the negative phenomena caused by anesthesia, there are a number of measures, including pharmacological therapy and additional care measures for experimental animals after anesthesia procedures. These measures are described for drugs such as acetaminophen, acetylsalicylic acid, butorphanol, codeine, fentanyl + medetomidine, ibuprofen, ketamine + xylazine, mepiridine, methadone, morphine, nalbufen, nalorphine, oxymorphine, phenobarbital / zolotophazine, tylepaxol and a number of others [6]. For a combination of drugs Zoletil $^{\circledR}$ (Zoletil20, 50 or 100) and XilaVet (Xila (xylazine)), measures that prevent the development of negative effects on the animal's body are insufficiently developed and described in the literature $[7,8]$, although the action of a combination of dissociative anesthetics and alpha-2-agonists is detailed investigated in laboratory animals [9-11]. Xilazine is an alpha2-adrenergic agonist, is a muscle relaxant and antihypertensive agent. It is use as a treatment of chronic drug addiction is considered justified [12]. Simultaneously, according to the ASA (American Society of Anesthesiologists), the use of Zoletil ${ }^{\circledR}$, a complex injection anesthetic for veterinary medicine, has a wide range of adverse effects. Thus, it is inappropriate for use in the surgical stage of anesthesia. The reason for this is the fact that Zoletil ${ }^{\circledR}$ can cause serious functional disorders of the cerebral cortex. Nevertheless, the use of Zoletil ${ }^{\circledR}$ to study functions controlled by the centers of the limbic system is promising, since this drug induces dissociative anesthesia: it inhibits only certain areas of the brain, such as the thalamus and cortex, while other areas, in particular the limbic system remain active [13]. 
The purpose of this work is to develop a protocol for the withdrawal of a laboratory animal from xylazine-Zoletil ${ }^{\circledR}$ anesthesia and additional / concomitant drug therapy, as well as measures for caring for the animal in order to reduce negative symptoms caused by regular anesthesia with these drugs.

\section{Research methods}

This project was approved by the Commission on the Ethics of Animal Experiments at the Southern Federal University (Russia) (protocol No. 1, April 28, 2018), which operates in accordance with the European Convention for the Protection of Vertebrate Animals used for Experiments or for Other Scientific Purposes (1986), "Rules for Conducting Work with Experimental Animals" [14].

We used adult male Norway domesticated rats (Rattus norvegicus) ( $\mathrm{n}=93$ ) weighing 490 grams, which underwent implantation of a matrix of microelectrodes into the dorsal region of the olfactory bulb for the chronic study of the functions of the olfactory system. After a recovery period of at least 7 days, the animals were introduced into the experiment, during which every 14 days for 6 months they were subjected to xylazine-Zoletil ${ }^{\circledR}$ anesthesia, after which the bioelectric activity of the olfactory bulb was studied, including the registration of pneumogram.

The animals were kept in a conventional vivarium in individual cages with an area of $1176 \mathrm{~cm} 2$ (model R-1) at a temperature of $22-24^{\circ} \mathrm{C}$ and a humidity of $65-75 \%$. A mixture of sawdust of the third fraction and compressed absorbent pellets made of wood material was used as a bedding material. Feeding was carried out with complete ration feed PK 120-2_35 at the rate of 35-45 grams per day per head; water without restrictions on consumption.

The drugs Xyla (xylazine) (Interchemie werken "De Adelaar" BV, Netherlands) and "Zoletila 50" (Zoletil 50) (Virbac Sante Animale, France) were used for anesthesia, the introduction of which was carried out according to the following scheme: the mixture was injected intramuscularly Xyla ( $0.05 \mathrm{ml} / \mathrm{kg}$ weight) and Zoletila50 (0.5 mg/kg weight).

The animals were divided into groups: control $(n=43)$ and experimental $(n=50)$. The control group was treated according to the standard scheme [13]. The experimental group used the following therapeutic measures to reduce the level of salivation, bronchial hypersecretion during the experiment and at the stage of recovery from xylazine-Zoletil ${ }^{\circledR}$ anesthesia. 30 minutes before the introduction of xylazine, premedication with atropine sulfate at a dose of $0.1 \mathrm{ml} / \mathrm{kg}$ of body weight was carried out intramuscularly. After the end of the experiment (average duration of 1.5 hours), the animal was injected intramuscularly with Cordiamine at a dose of $0.3 \mathrm{ml} /$ $\mathrm{kg}$ of body weight, Antisedan ${ }^{\circledR}$ at a dose of 1: 1 of the calculated dose of Xila ${ }^{\circledR}$ for this animal, subcutaneously - Ringer-Locke's solution mixed with glucose $40 \%$ at a dose of $1.5 \mathrm{ml}$ and $0.5 \mathrm{ml}$, respectively.
The following changes have been made to the rules for the care and maintenance of this group of animals. The animals were on a starvation diet 12 hours before anesthesia. During the recovery from anesthesia, the animal was placed in a cage with sides insulated from the outside, located on a heating pad. The temperature of the pad was adjusted manually at the control unit to maintain body temperature of $37.5^{\circ} \mathrm{C}$. After coming out of anesthesia (after about 5.5 hours), the animal was placed in a cage with normal conditions.

\section{Research results}

One of the most controllable indicators of the effect of anesthesia on the animal organism is monitoring the frequency and depth of breathing [15]. The study of respiration during experimental sessions accompanied by xylazineZoletil $^{\circledR}$ anesthesia showed that cases with a favorable outcome of anesthesia with the use of these drugs are characterized by the following changes in the pneumogram of rats: compared with the state of wakefulness (Figure 1), after entering the deep stage of anesthesia, the frequency respiration is significantly reduced, while the nature of the teeth of the pneumogram, as a rule, changes during this stage of anesthesia (Figure 2A-B). Recovery from anesthesia is characterized by an increase in the respiratory rate (Figure 3 ). A negative reaction to xylazine-Zoletil ${ }^{\circledR}$ anesthesia was characterized by the formation of irregular breathing with a significant change in the amplitude of the teeth on the pneumogram up to respiratory arrest (Figure 4).

During anesthesia, in animals with a negative reaction to xylazine-Zoletil ${ }^{\circledR}$ anesthesia, in addition to disturbances in the rhythm and frequency of respiratory movements, hypersalivation and apnea were noted. With each subsequent drug addiction, negative symptoms intensified. At the stage of recovering from anesthesia, the animals showed a perversion of appetite and choking with vomit were often observed.

Long-term use of xylazine-Zoletil ${ }^{\circledR}$ anesthesia led to the development of tolerance to Zoletil ${ }^{\circledR}$ and the need to increase its dose (up to double) to achieve the desired effect (Figure5). In these cases, the cause of death was polyetiological in nature (myocardial infarction, pulmonary edema and cerebral edema, in some cases - oncology).

According to the analysis, the percentage of death of animals in the control group was higher than in the experimental group throughout the experiment (Figure 6).

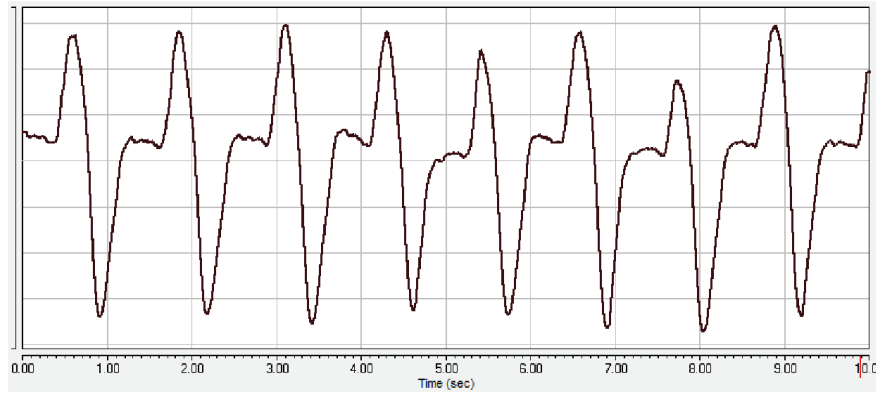

Figure 1: An example of a pneumogram of a rat in the waking state.

Citation: Vovk AN, Karantysh GV, Kosenko PO, Medvedev DS (2020) Principles of therapy and care of laboratory animals after chronic administration into Xylasine-Zoletyl® Anesthesia. Int J Vet Sci Res 6(2): 114-117. DOI: https://dx.doi.org/10.17352/ijvsr.000062 
The greatest increase in the mortality rate of animals in the control group fell on 5-6 months of the experiment. At the same time, in the control group, $72 \%$ of the animals died during the entire observation period, and in the experimental group - only $24 \%$. The most common causes of death are shown in Table 1.

\section{Conclusion}

The use of xylazine-Zoletil ${ }^{\circledR}$ anesthesia in a chronic experiment has features. The advantage of this type of anesthesia is the ability to conduct studies of body functions controlled by the structures of the limbic system. However, the presence of serious side effects of this type of anesthesia is the basis for limiting its use during chronic anesthesia [6].

The results of the study prove the possibility of using xylazine-Zoletil ${ }^{\circledR}$ anesthesia for this purpose as well. The condition for the success of its chronic use is the observance of the measures described in this work for the conduct of therapy and the observance of special measures for the care of animals after each anesthesia.

The use of therapeutic measures and changes in the conditions of keeping the animals of the experimental group made it possible to reduce the mortality rate, as well as to

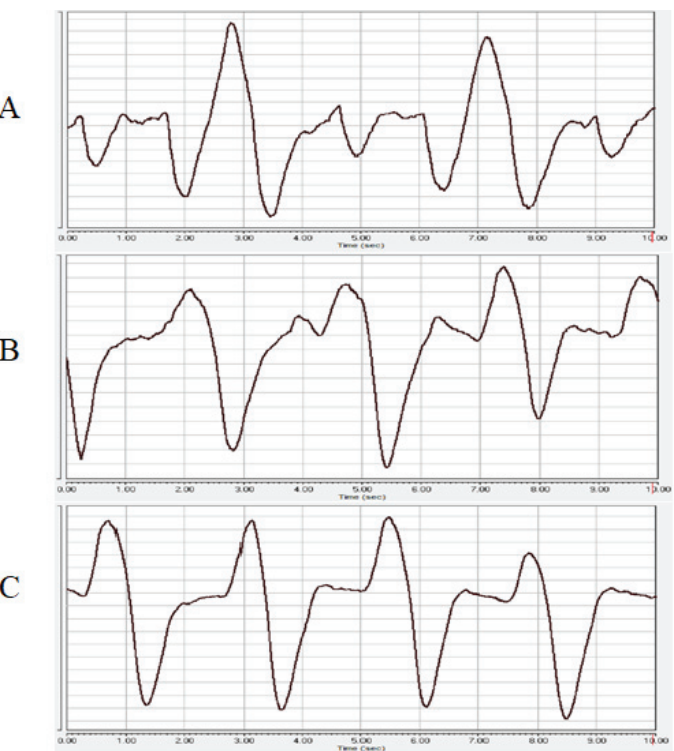

Figure 2: Changes in the nature of the pneumogram of rats at different times after the development of the stage of deep anesthesia: $0.5 \mathrm{~h}(\mathrm{~A}), 1.0 \mathrm{~h}(\mathrm{~B}), 1.5 \mathrm{~h}(\mathrm{C})$

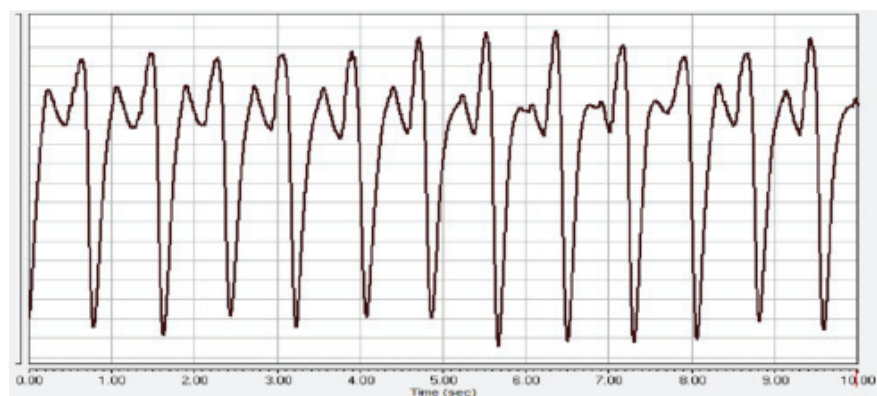

Figure 3: An example of a pneumogram of rats upon recovery from anesthesia.

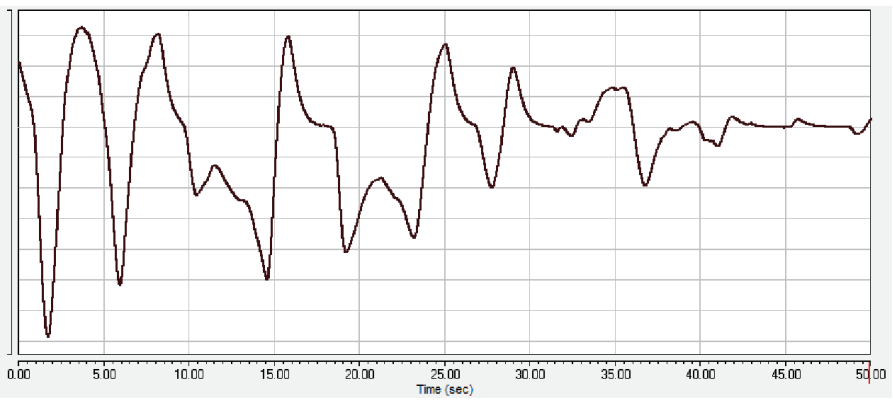

Figure 4: An example of a pneumogram of rats with a negative reaction to xylazineZoletil® anesthesia.

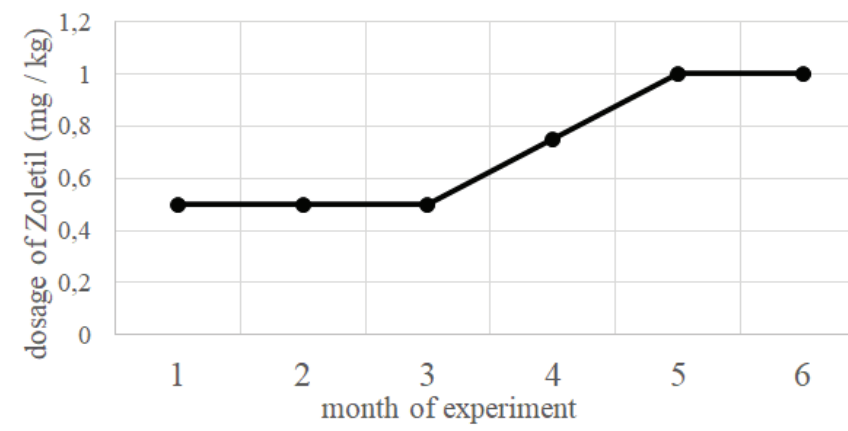

Figure 5: Changing the dosage of Zoletil® in the dynamics of the experiment conducted on rats of the control group.

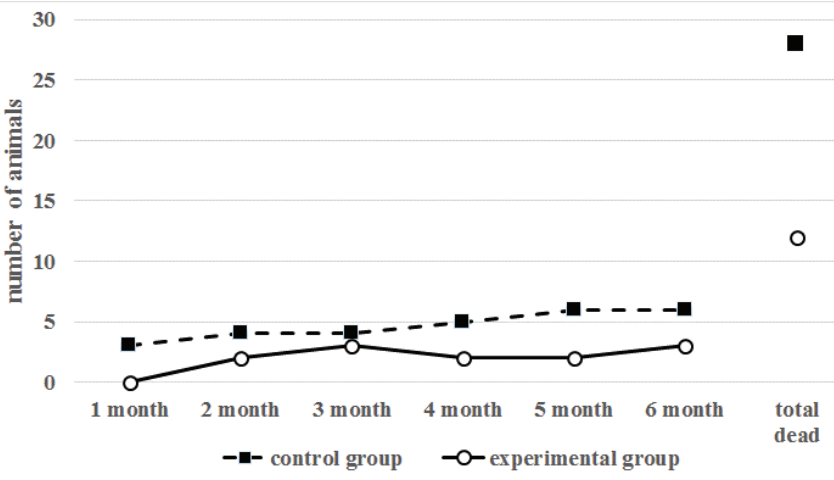

Figure 6: The mortality rate of animals in the control and experimental groups in the dynamics of a chronic experiment, the total number of dead rats.

increase their resistance to chronic drug addiction. Thus, the use of atropine sulfate as a premedication made it possible to minimize of salivation and salivation during and after anesthesia, which reduced the cases of flooding with saliva and minimized the effect of salivation on the results of the study of the olfactory system function. The introduction of Cordiamine after each session of the experiment helped to reduce the phenomenon of apnea at the stage of recovery from anesthesia. So, if in the control group, after 3 months of the experiment during anesthesia, the development of apnea was observed in all animals, in the experimental group this phenomenon was characteristic for $1 / 4$ of the animals at the 3rd month of the experiment, at 4-5 months - for $1 / 3$, on the 6th month of the experiment - for $1 / 2$ rats (out of the number of survivors). The introduction of Antisedan ${ }^{\circledR}$ provided a decrease in the time of recovery from the state of anesthesia by about half. Transferring the animal to a starvation diet 12 hours before

Citation: Vovk AN, Karantysh GV, Kosenko PO, Medvedev DS (2020) Principles of therapy and care of laboratory animals after chronic administration into Xylasine-Zoletyl® Anesthesia. Int J Vet Sci Res 6(2): 114-117. DOI: https://dx.doi.org/10.17352/ijvsr.000062 
Table 1: Causes of death of animals under conditions of chronic xylazine-Zoletil ${ }^{\circledR}$ anesthesia.

\begin{tabular}{|c|c|c|}
\hline \multirow{2}{*}{ Cause of death } & \multicolumn{2}{|c|}{$\begin{array}{c}\text { Number of deaths / } \\
\text { (\% of the number of rats in the group) }\end{array}$} \\
\cline { 2 - 3 } & Control group & Experimental group \\
\hline Respiratory arrest of central origin & $13 /(30 \%)$ & $5(10 \%)$ \\
\hline Edema of the brain and lungs & $7 /(16 \%)$ & $3(6 \%)$ \\
\hline $\begin{array}{c}\text { Other reasons: myocardial infarction, } \\
\text { hemorrhagic stroke, etc. }\end{array}$ & $8 /(18 \%)$ & $4(8 \%)$ \\
\hline
\end{tabular}

anesthesia made it possible to exclude vomiting during and after anesthesia. If the animals were not transferred to a diet, in $2 / 3$ of the cases, in the dead animals after anesthesia, abundant discharge from the mouth was revealed, in the esophagus and stomach - mushy contents.

The use of a heating pad after the operation eliminated the influence of external temperature changes on the animal's body. General detoxification therapy using subcutaneous injection of Ringer-Locke's solution with glucose [16] has shown its effectiveness in preventing the development of anesthesia tolerance: chronic anesthesia for six months did not lead to the need to increase the dose of anesthesia to achieve the desired effect. If signs of respiratory distress appear on the pneumogram in response to xylazine-Zoletil ${ }^{\circledR}$ anesthesia, it is necessary to suspend the experiment, perform therapeutic procedures (administration of Cordiamine, Antisedan ${ }^{\circledR}$ and detoxification therapy), followed by placing the animal in an individual cage with a heating pad to maintain a constant body temperature.

These recommendations can form the basis for the formation of a protocol for animal management when using chronic xylazine-Zoletil ${ }^{\circledR}$ anesthesia.

\section{References}

1. Luca C, Salvatore F, Vincenzo DP, Giovanni C, Attilio ILM (2018) Anesthesia protocols in laboratory animals used for scientific purposes. Acta Biomed 89: 337-342. Link: https://bit.ly/2ZgcOYq

2. Kawai S, Takagi Y, Kaneko S, Kurosawa T (2011) Effect of three types of mixed anesthetic agents alternate to ketamine in mice. Exp Anim 60: 481-487. Link: https://bit.ly/3h8IAxT

3. Kirihara Y, Takechi M, Kurosaki K, Kobayashi Y, Kurosawa T (2013) Anesthetic effects of a mixture of medetomidine, midazolam and butorphanol in two strains of mice. Exp Anim 62: 173-180. Link: https://bit.ly/3IRA7lf

4. Risling TE, Caulkett NA, Florence D (2012) Open-drop anesthesia for smal laboratory animals. Can Vet J 53: 299-302. Link: https://bit.ly/3i6eiff

5. Uhlig C, Krause H, Koch T, Gama de Abreu M, Spieth PM (2015) Anesthesia and Monitoring in Small Laboratory Mammals Used in Anesthesiology, Respiratory and Critical Care Research: A Systematic Review on the Current Reporting in Top-10 Impact Factor Ranked Journals. PLoS One 10: e0134205. Link: https://bit.ly/2DErtVW

6. Karmarkar SW, Bottum KM, Tischkau ShA (2010) Considerations for the Use of Anesthetics in Neurotoxicity Studies. Comp Med 60: 256-262. Link: https://bit.ly/35dwno4
7. Patent: Method for anaesthetization in rats at staged experiment in simulated endometriosis.

8. Chen L, Yin YP, Wu CC, Jiang S (2015) Anesthesia with intraperitoneal tiletamine/zolazepam, xylazine, and tramadol in mice. Med Weter 71: 219-223. Link: https://bit.ly/3i6a6MH

9. Ferrari L, Turrini G, Rostello C, Guidi A, Casartelli A, et al. (2005) Evaluation of two combinations of domitor, Zoletil 100 and euthatal to obtain longterm non recovery anestesia in sprague-dawley rats. Journal of the American Association for Laboratory Animal Science 55: 256-264. Link: https://bit.ly/331SoDG

10. Saha D, Saha A, Malik G, Astiz ME, Rackow EC (2007) Comparison of cardiovascular effects of tiletaminezolazepam, pentobarbital and ketamine-xylazine in male rats. J Am Assoc Lab Anim Sci 46: 74-80. Link: https://bit.ly/3IZ8dDK

11. Spinella G, Vilar JM, Anastasi C, Santana-del-Pino A (2012) Three combinations of clonidine in association with tiletamine-zolazepam for anaesthesia induction in rats: evaluation of reflexes and pain sensibility. Veterinarn Medicina 57: 536-542. Link: https://bit.ly/2ZgdCfu

12. Doran GS, Bradbury LA (2015) Quantitation of the anaesthetic xylazine in ovine plasma by LC-MS/MS. J Chromatogr B 997: 81-84. Link: https://bit. ly/2EW056x

13. Ma N, Li X, Wang H, Gao L, Xiao J (2019) Effects of Tiletamine-xylazinetramadol Combination and its Specific Antagonist on AMPK in the Brain of Rats. J Vet Res 63: 285-292. Link: https://bit.ly/3jWOdSq

14. (1986) European Convention for the Protection of Vertebrate Animals used for Experimental and other scientific purposes. Strasburg: Counsil of Europe 51 Link: https://bit.ly/3bAUwGd

15. Olsen AK, Smith DF (2013) Anaesthesia for positron emission tomography scanning of animal brains. Laboratory Animals 47: 12-18. Link: https://bit.ly/325iPJq

16. Flannery A, Adkins D, Cook A (2014) Unpeeling the Evidence for the Banana Bag: Evidence-Based Recommendations for the Management of AlcoholAssociated Vitamin and Electrolyte Deficiencies in the ICU. Critical Care Medicine 44: 1545-1552. Link: https://bit.ly/3i5272k

Discover a bigger Impact and Visibility of your article publication with

\section{Peertechz Publications}

\section{Highlights}

* Signatory publisher of ORCID

* Signatory Publisher of DORA (San Francisco Declaration on Research Assessment)

* Articles archived in worlds' renowned service providers such as Portico, CNKI, AGRIS, TDNet, Base (Bielefeld University Library), CrossRef, Scilit, J-Gate etc.

* Journals indexed in ICMJE, SHERPA/ROMEO, Google Scholar etc.

* OAI-PMH (Open Archives Initiative Protocol for Metadata Harvesting)

* Dedicated Editorial Board for every journal

* Accurate and rapid peer-review process

* Increased citations of published articles through promotions

* Reduced timeline for article publication

Submit your articles and experience a new surge in publication services (https://www.peertechz.com/submission).

Peertechz journals wishes everlasting success in your every endeavours.

Copyright: @ 2020 Vovk AN, et al. This is an open-access article distributed under the terms of the Creative Commons Attribution License, which permits unrestricted use, distribution, and reproduction in any medium, provided the original author and source are credited.

Citation: Vovk AN, Karantysh GV, Kosenko PO, Medvedev DS (2020) Principles of therapy and care of laboratory animals after chronic administration into Xylasine-Zoletyl® Anesthesia. Int J Vet Sci Res 6(2): 114-117. DOI: https://dx.doi.org/10.17352/ijvsr.000062 